\title{
Evolução teórico-metodológica dos estudos de comportamento informacional de usuários
}

\author{
Kelley Cristine Gonçalves Dias Gasque \\ Doutora em ciência da informação pela Universidade de Brasília, \\ professora adjunta da Universidade Federal de Goiás. \\ E-mail: kelleycristinegasque@hotmail.com

\section{Sely Maria de Souza Costa} \\ Doutora em ciência da informação pela Loughborough University, \\ professora adjunta da Universidade de Brasília. \\ E-mail:selmar@unb.br
}

\section{Resumo}

Este artigo visa a contribuir para o conhecimento mais aprofundado sobre estudos de comportamento informacional de usuários com base em como são tratados na literatura da ciência da informação nas últimas seis décadas. Para tanto, a análise se fundamenta nas revisões publicadas no periódico Annual Review of Information Science and Technology (Arist) e em outros trabalhos que complementam o tema abordado, mostrando sua evolução teórica e metodológica. Uma diferença crucial está relacionada à mudança conceitual observada, a qual denota a ampliação da visão epistemológica dos estudos. Tal mudança referese, especialmente, à nova terminologia adotada, que passa de "estudos de usuários" ou "necessidades e uso de informação" para "comportamento informacional de usuários". Trata-se, contudo, não somente de alteração terminológica, mas, sobretudo, de mudança paradigmática, resultado de transformações no modo como o tópico é definido e abordado, e na forma como é investigado.

\section{Palavras-chave}

Comportamento informacional. Estudos de usuários. Necessidades e usos da informação. Evolução paradigmática.

\section{Theoretical methodological evolution of the studies of information behavior of users}

\begin{abstract}
The objective of this article is to contribute to a deeper understanding of how user information behaviour studies have been dealt with in literature on information science for the last six decades. The analysis is based on the reviews published in the journal Annual Review of Information Science and Technology (Arist), as
\end{abstract}

well as on additional works that complement the topic approached showing its theoretical and methodological evolution. analyses. A crucial difference identified is related to the conceptual change occurred, showing a wider epistemological view of the studies. This change, on the other hand, is referred mainly to the terminology used to define the topic, which is changed from "studies of users" or "needs and use of information" to informational behavior of users". The change, however, is not only terminological but also a paradigmatic change, as a result of transformation in how the topic is defined and approached, as well as how the research is carried out.

\section{Keywords}

Information behaviour. User studies. Information needs and use. Paradigmatic evolution.

\section{INTRODUÇÃO}

Embora se observe no Brasil, nos últimos anos, a emergência de pesquisas intituladas Comportamento Informacional de Usuários, em geral tais investigações ainda são conhecidas como "estudos de necessidades", contidos no tópico "estudos de usuários"1. Tanto Wilson (2000) como Pettigrew, Fidel e Bruce (2001) entendem o comportamento informacional como campo oriundo das limitações dos estudos de usuários e, portanto, constituindo uma evolução desses estudos.

\footnotetext{
1 Para este estudo, foi realizado levantamento quantitativo dos termos 'comportamento informacional', 'busca e uso da informação', 'busca da informação', 'uso da informação', 'necessidades de informação' e 'estudos de usuários' no catálogo on-line do IBICT (Instituto Brasileiro de Informação em Ciência e Tecnologia), nas bases LISA (Library and Information Science Abstracts), ERIC (Education Resource Information Center) e no buscador Scirus com o objetivo de se ter uma primeira visão do assunto. As buscas mostram que o termo 'necessidades de informação' é o mais utilizado. $\mathrm{O}$ motivo pode estar relacionado à tradição, uma vez que os primeiros estudos focavam-se nas necessidades dos usuários. Observa-se, ainda, que o termo 'comportamento informacional', mesmo tendo sido cunhado recentemente, começa a ser empregado de forma mais intensa.
} 
Os estudos de revisão sobre comportamento informacional descrevem o cenário das grandes questões tratadas desde as primeiras pesquisas na área até os dias atuais, em que se delineiam as características principais de cada década, consideradas, desse modo, os paradigmas vigentes para o direcionamento das análises. Nessa perspectiva, paradigma refere-se às crenças e aos valores subjacentes à prática científica, entendido como um modelo de ciência que serve de referência para o fazer científico durante determinado período de tempo (KUHN, 1962).

Este artigo apresenta os paradigmas em vigor ao longo do desenvolvimento do tema, de acordo com cada contexto analisado, principalmente o contemporâneo. Para tanto, o método utilizado foi a pesquisa documental, envolvendo a identificação, análise e sumarização das principais discussões do Annual Review of Information Science and Technology (Arist), que condensa a literatura de determinados períodos, fornecendo, assim, os principais tópicos para estudo.

Para complementar as abordagens do Arist, examinaram-se outros trabalhos relevantes da literatura internacional. O resultado da análise permitiu identificar a terminologia, a metodologia e as tendências sobre o tópico investigado.

\section{CONSTRUÇÃO DO CONCEITO}

Ao analisar as revisões da literatura sobre necessidades e uso de informação, observa-se uma evolução no enfoque dos estudos, partindo de uma perspectiva mais restrita para uma mais abrangente tanto no que se refere aos conceitos e metodologias como também aos grupos de usuários estudados. Em 1970, Brittain definiu os estudos de usuários como aqueles que comportam os aspectos de uso, demanda e necessidades. $\mathrm{Na}$ visão do autor, os relativos ao uso objetivam conhecer os mecanismos de busca da informação e de uso de fontes de informação. Já os de demanda referem-se às solicitações feitas a um sistema. A grande crítica de Brittain residia nas pesquisas sobre necessidades, as quais, muitas vezes, eram confundidas com as de demanda devido à imprecisão do próprio conceito de necessidade.
Figueiredo (1994) entende estudos de usuários como as investigações realizadas para conhecer as necessidades de informação dos usuários ou para avaliar o atendimento das necessidades de informação pelas bibliotecas e pelos centros de informação. Wilson (1999), no entanto, após várias análises sobre o tópico, amplia significativamente a ideia, salientando que o tema pode ser compreendido de maneira mais abrangente. Para tanto, deve-se inseri-lo no campo do comportamento humano e denomina-lo 'comportamento informacional'. Esse tipo de ação refere-se às atividades de busca, uso e transferência de informação nas quais uma pessoa se engaja quando identifica as próprias necessidades de informação.

Em artigo publicado em 2000, Wilson propõe quatro definições relacionadas ao comportamento informacional:

- comportamento informacional: a totalidade do comportamento humano em relação ao uso de fontes e canais de informação, incluindo a busca da informação passiva ou ativa;

- comportamento de busca da informação: a atividade ou ação de buscar informação em consequência da necessidade de atingir um objetivo;

- comportamento de pesquisa de informação: o nível micro do comportamento, em que o indivíduo interage com sistemas de informação de todos os tipos;

- comportamento do uso da informação: constitui o conjunto dos atos físicos e mentais e envolve a incorporação da nova informação aos conhecimentos prévios do indivíduo.

Em consonância à proposta de Wilson (2000), Pettigrew, Fidel e Bruce (2001) compreendem o 'comportamento informacional' como as atividades que envolvem as necessidades dos sujeitos e de como buscam, usam e transferem a informação em diferentes contextos. $\mathrm{Na}$ literatura recente da ciência da informação, portanto, o conceito de comportamento informacional reflete as noções identificadas nos estudos sobre usuários de 
informação. Mais que isso, identificam-se novas questões introduzidas no âmbito do tema.

A ideia de contexto ressaltada por Courtright (2007) norteia pesquisas e suscita preocupações como a definição de limites, os fatores que influenciam a prática informacional e as novas tecnologias. A autora identifica quatro sentidos usados para o termo. Primeiro, a noção de 'contêiner', em que os elementos existem objetivamente em torno dos atores. Segundo, o meio de construção de significado, em que se analisa o ponto de vista do autor. Terceiro, o conceito de construção social, em que os atores elaboram a informação por meio da interação social. Finalmente, a questão relacional, em que os conceitos de ator social e contexto estão vinculados entre si.

À noção de contexto subentendem-se expressões inter-relacionadas, como situação, complexidade das tarefas, problemas, contornos, normas, cultura, capital social e redes sociais, dentre outras, ampliando a estrutura teórica da área. Apesar de se observar, na literatura da ciência da informação, um sistema conceitual básico sobre os estudos de comportamento informacional humano, pode haver variações em relação aos conceitos e às proposições, dependendo da abordagem empregada, seja comportamentalista, cognitivista, seja social e multifacetada. Logo, para analisar as principais questões desses estudos e sem desenvolvimento, é necessário construir um panorama desde suas origens.

\section{DOS 'ESTUDOS DE USUÁRIOS' AOS 'ESTUDOS DE COMPORTAMENTO INFORMACIONAL'}

\section{Décadas de 50 e 60}

As primeiras investigações no campo dos estudos de usuários foram realizadas após a década de 1940, impulsionadas por dois eventos. O primeiro, a Conferência de Informação Científica da Sociedade Real, em 1948, no Reino Unido. O segundo, a Conferência Internacional de Informação Científica, em Washington, Estados Unidos, em 1958. Nessas ocasiões, foram apresentados trabalhos que despertaram a atenção dos participantes para a importância dos estudos das necessidades dos usuários.

A revisão de Menzel (1966) acerca de necessidades e uso de informação nas áreas de ciência e tecnologia inaugurou uma série de revisões sobre o assunto. O autor realizou análises quantitativas de 1963 a 1965 para estabelecer definições e conceitos do tópico. Menzel argumentava que os estudos de necessidades e usos são aqueles voltados para o comportamento e as experiências dos cientistas e tecnólogos em face dos canais de informação. Baseados em dados empíricos e observações do comportamento, eram organizados em três categorias: estudos de avaliações e preferência, estudos de uso e estudos de disseminação.

A segunda revisão, realizada em 1967 por Saul e Mary Herner, complementou o trabalho de Menzel. A pesquisa cobriu as publicações de 1966 e algumas de 1965 não avaliadas na primeira etapa. Foram detectados sete problemas nas publicações analisadas. O primeiro refere-se ao uso de poucas técnicas de pesquisa. O segundo, à diversidade de tipos de usuários em que essas técnicas são aplicadas. O terceiro, à variabilidade e ambigüidade da linguagem na discussão das técnicas usadas e nos resultados. O quarto, à carência de inovação. O quinto, ao insucesso em fundamentar os resultados obtidos. O sexto, ao fracasso em aprender com os erros. Finalmente, o problema da frequente ausência de projetos de experimentos rigorosos.

Paisley (1968) fez a terceira revisão dos estudos de necessidades e de uso da informação, abrangendo alguns trabalhos surgidos em fins de 1966 e durante o ano de 1967. Afirmou que muitos apresentavam problemas metodológicos, que os tornavam inconclusivos. Neles, não se consideravam fatores como a grande quantidade de fontes de informação disponíveis; o contexto em que as informações são usadas; a motivação, a orientação profissional e outras características pessoais; os sistemas social, político, econômico e outros que afetam intensamente os usuários e o trabalho, alem das consequências do uso da informação. Ainda assim, Paisley constatou o crescimento e o amadurecimento da qualidade 
dos trabalhos que poderiam oferecer diretrizes para conceber e avaliar sistemas de informação. Sugeriu, porém, que novos ensaios deveriam usar metodologia eclética para fortalecimento da teoria.

Os trabalhos publicados em 1968 foram revisados por Allen (1969), usando a estrutura sistêmica proposta por Paisley (1968), na qual o usuário se localiza em uma série de sistemas concêntricos. Allen identificou a existência de muitos autores que usaram instrumentos inadequados para a área das ciências sociais. Em contrapartida, havia um corpo qualificado de boas pesquisas no campo. Outro ponto destacado relacionava-se ao fato de que muitos textos não deixavam claro se o sujeito da pesquisa era cientista ou tecnólogo, visto que as duas populações apresentavam diferenças comportamentais, particularmente em relação à forma de comunicação.

Allen (1969) concluiu a revisão observando que muitos estudos eram ainda realizados por indivíduos preocupados com problemas locais, sendo usualmente de baixa qualidade e com poucas contribuições para a ciência da informação. Entretanto, detectou um colégio invisível composto por estudiosos do tópico, em várias instituições. $\mathrm{Na}$ visão do autor, eles poderiam desenvolver uma estrutura social, desde que atuassem em disciplinas específicas.

As pesquisas realizadas entre os anos de 1950 e meados da década de 1960, primeiro período dos estudos de usuários, concentravam-se nos indivíduos que utilizavam informação científica e tecnológica. Abrangiam um conjunto relativamente limitado de assuntos com membros de disciplinas específicas ou da comunidade científica como um todo. A técnica mais comumente empregada era a dos questionários autoadministrados. As investigações tinham natureza exploratória e os resultados eram descritos em termos gerais a partir da reunião de dados sobre hábitos e necessidades. Essa abordagem generalista permitiu o desenho de sistemas de informação de acordo com a maioria das necessidades dos usuários. Entretanto, como os resultados às vezes fossem contraditórios, muitos estudos falharam na tentativa de dar suporte à estruturação dos sistemas de informação (MARTYN, 1974).

Em meados de 1960, os estilos mais generalistas começaram a rarear. Apesar da extensa produção de levantamentos sobre usuários, segundo Martyn (1974), nem sempre eles eram de boa qualidade. Alguns utilizaram instrumentos mais sofisticados, como técnicas de observação indireta e análise de citação. Métodos sociológicos mais refinados foram aplicados aos estudos de sistemas informais de transmissão de informação, possibilitando a descrição de colégios invisíveis e nomeação de gatekeepers, além da compreensão mais profunda sobre modos de a informação ser adquirida e usada. Todavia, esses estudos tiveram pouco impacto sobre os designers de sistemas de informação.

\section{Década de 70}

O trabalho de Lipetz (1970) inaugurou as revisões da década de 1970, enfatizando os estudos que podiam ser transpostos para outras situações. Os estudos de necessidades e uso da informação foram conceituados como atividades racionais voltadas para um fim específico, com o objetivo de explicar os fenômenos observados, predizer instâncias do uso de informação e controlar sua utilização manipulação de condições essenciais. Os objetivos seriam alcançados se precedidos de atividades de descrição, definição dos conceitos e teorização das relações causais ou qualitativas entre uso da informação e os fatores associados. Lipetz (1970) agrupou as pesquisas em três seções - levantamento e medidas, metodologia e teoria - subdivididas, de acordo com a proposta de Paisley (1968), em subsistemas nos quais os cientistas e tecnólogos pudessem ser identificados.

Lipetz (1970) concluiu a revisão destacando que os estudos de necessidades e usos da informação, como disciplina científica, encontravam-se ainda em sua infância. Contudo, grande vigor e capacidade de crescimento foram percebidos, mesmo considerando a dinamicidade e a relatividade em que divergem as necessidades com o tempo, o sujeitos, o objetivo, 
a localização, as alternativas e outras variáveis. $\mathrm{O}$ autor sugeriu que, antes do esboço da teoria de um sistema de informação ideal para as complexas necessidades de qualquer idade, são indispensáveis mais dados quantitativos das necessidades e do comportamento humano.

Em seguida, Crane (1971) apresentou revisão sobre o tema cobrindo alguns estudos não incluídos na revisão anterior e outros recentes - o que perfazia cerca de um ano. O presente artigo não discute o trabalho de Crane por não ter sido possível ter acesso ao seu texto. No entanto, sabe-se que a autora abordou questões relacionadas aos métodos então adotados nos estudos de necessidades e uso de informação, corroborando a visão crítica de que careciam de mais rigor científico.

Lin e Garvey (1972) fizeram a revisão sobre necessidades e usos de informação na ciência e na tecnologia, referentes ao ano de 1971, verificando que abordagens sistemáticas sobre o assunto tornaram-se um fenômeno internacional. Utilizaram um modelo de comunicação científica, especificando as fases de necessidades, de busca, de transferência e de uso da informação. As limitações do modelo relacionavam-se ao foco voltado para a informação, apesar do reconhecimento da existência de pontos de convergência entre os padrões de comportamento dos cientistas e tecnólogos e a estrutura socioeconômica da ciência e da tecnologia; à ausência de análises individuais de cientistas e tecnólogos; e, por fim, à introdução de conceitos sem definições precisas.

Os autores sugeriram, à guisa de conclusão, ampliar as discussões sobre quatro tópicos considerados críticos. O primeiro era a definição clara do conceito de colégio invisível. O segundo relacionava-se ao intercâmbio de informações e às pessoas atuantes como gatekeepers a fim de averiguar as informações fornecidas por elas e as relações com as suas funções, com o objetivo de traçar o mapa do fluxo da informação no ambiente externo da organização. O terceiro item era a lacuna evidenciada pela carência de integração entre os pesquisadores e os designers dos sistemas informacionais. Por fim, o tópico mais preocupante referia-se à conceituação do comportamento de cientistas e tecnólogos no estudo dos elementos dos sistemas de interação entre informações e usuários reais e potenciais. Assim, os modelos de comunicação poderiam auxiliar no mapeamento dessas inter-relações.

Martyn (1974) iniciou a oitava revisão do Arist assegurando que 'a era dos dinossauros' havia terminado para os estudos de usuários. Analisando o que fora editado em 1972 e 1973, verificou que o número de publicações fora consideravelmente menor do que nos anos anteriores. Sua abordagem dividiu-se em três tópicos. No primeiro, estudos direcionados para sistemas, foram analisadas pesquisas realizadas com o objetivo de orientar ou mudar serviços específicos. No segundo, foram analisados trabalhos do ponto de vista dos usuários sobre os componentes da rede de comunicação científica e técnica. No último tópico, intitulado Background Research, foram narradas experiências voltadas à ecologia da informação ou com metodologias inovadoras.

$\mathrm{Na}$ conclusão, Martyn ressaltou que se passou a reconhecer a complexidade e a singularidade das necessidades de informação dos usuários, observando que a metodologia dos estudos de usuários se mostrava inadequada para esclarecer a natureza e as necessidades de quem buscava informação. Além disso, seria impossível prover todas as informações necessárias em todas as circunstâncias. Nessa perspectiva, demandavam-se olhares que não estivessem voltados especificamente para os sistemas de informação, visando a ampliar a compreensão dos usuários e de suas necessidades, uma vez que o foco era o inter-relacionamento de pessoas e ideias.

A revisão de Crawford (1978) abrangeu 95 publicações sobre estudos de necessidades e de busca da informação, impressas entre 1975 e 1977, identificados no Information Science Abstracts Library Literature e em fontes informais. A autora, tal como o fizeram Brittain (1970) e Martyn (1974), 
reconheceu a dificuldade em definir, isolar e mensurar o conceito de necessidade por envolver níveis diferentes de consciência nem sempre claros para o indivíduo. Ao contrário, a informação como demanda expressa para um objetivo específico e para uso em um ambiente particular podia ser definida mais facilmente, embora os objetivos não fossem logo identificados e a precisão da comunicação nem sempre fosse possível. Quanto às metodologias empregadas, a crítica de Crawford recaiu sobre a escolha de somente um método ou a combinação de métodos padronizados. As estratégias mais comuns utilizadas nas pesquisas eram os levantamentos (surveys) em oposição às experimentações ou simulações, ainda pouco comuns.

Crawford (op. cit) identificou maior amplitude de temas abordados, diferentemente dos resultados contidos no primeiro Arist (Menzel, 1966), que se centravam nas necessidades e na busca de informação em ciência e tecnologia. Na conclusão, a autora lista cinco pontos resultantes da análise. O primeiro refere-se à inclusão de pesquisadores de várias disciplinas nos estudos de uso da informação. O segundo vincula-se à ampliação do levantamento das necessidades de vários grupos, como idosos, populações urbanas, minorias e cientistas e técnicos. O terceiro relaciona-se à evidência de maior refinamento das conceituações e metodologias, em que os conceitos das ciências sociais combinados com as técnicas quantitativas produziram casos efetivos. O quarto, a introdução da variável 'ambiente de uso da informação'. Finalmente, a distinção entre os aspectos cognitivos e sociais da informação, acrescentando novas perspectivas aos estudos.

Após a revisão de 1978, houve pausa de oito anos sobre o assunto nas publicações do Arist. A despeito disso, os estudos continuaram crescendo, impulsionados por intensas discussões que ocorriam na época. Um marco decisivo que incentivou novos esforços foi a criação, em 1976, do Centre for Research on User Studies (CRUS) na Universidade de Sheffield, Inglaterra, com o apoio do British Library Research and Development Department (BLRDD). O centro era constituído por especialistas cuja responsabilidade era torná-lo um núcleo nacional de expertise em estudos de usuários, abrangendo quatro áreas interligadas: pesquisa, educação, consultoria e informação (WILSON-DAVIS, 1977).

O paradigma predominante nas décadas entre 1950 e 1970 - o behaviorista - sustentava-se na crença de que a metodologia empregada para analisar o comportamento humano deveria dar ênfase à objetividade e a neutralidade. Mais que isso, embora as abordagens metodológicas adotadas fossem, de fato, pouco consistentes, algumas das críticas encontradas na literatura parecem refletir uma preocupação positivista, tendência natural das pesquisas até então.

Sobre o foco comumente adotado, Wilson (2000) acrescenta que muitos autores, antes de meados da década de 1970, estavam mais preocupados com o uso de sistemas do que com o uso da informação. No entanto, ainda nessa época, percebia-se a tendência em enfatizar o usuário e não mais o sistema per se. Era possível então, distinguir dois grupos de pesquisadores. O primeiro, orientado para o uso de unidades de informação (bibliotecas, centros de informação, dentre outros). O segundo, voltado ao comportamento de comunidades específicas de usuários na busca da informação necessária às suas atividades.

No gênero orientado para os usuários, um item importante desenvolvido pelo CRUS focalizava os não-usuários. Isso porque, de acordo com pesquisas anteriores, $70 \%$ da população do Reino Unido nunca havia usado bibliotecas ou centros de informação e de $50 \%$ a $60 \%$ jamais compraram um livro. Havia, portanto, a indicação de descobrir as informações necessárias e os meios usados por esses grupos para buscá-las. A hipótese era de que usavam diferentes redes de informação, compostas por amigos, vizinhos ou colegas de trabalho além de televisão, jornais ou outros meios. As unidades de informação compunham, na verdade, apenas uma parte da estrutura utilizada (WILSON-DAVIS, 1977).

As conclusões a que chegou Wilson-Davis (1977) revelam, pelo menos, dois pontos: o de que o foco adotado nos estudos - os usuários ou os sistemas - 
precisava ser ampliado, levando em conta não somente os sistemas formais constituídos de bibliotecas e outros centros de informação, mas também os informais; o segundo é o de que o comportamento informacional de usuários, por ser um processo natural do ser humano, envolve todo tipo de meios e canais de acesso requeridos para o atendimento das necessidades de informação.

\section{Décadas de 80 e 90}

Como dito anteriormente, a primeira revisão dessas duas décadas ocorreu oito anos após a última revisão da década de 1970. Dervin e Nilan (1986) abordaram, portanto, a literatura sobre a busca e o uso da informação a partir de 1978. Observaram que muitos estudos ainda estavam centrados nos sistemas e no paradigma tradicional.

São sete as características identificadas no paradigma tradicional. A primeira, a objetividade, em que a informação é entendida como algo com significado constante, correspondendo, de forma absoluta, à realidade. A segunda, o mecanicismo, cujo foco é sobre o sistema, não percebendo o usuário como indivíduo com objetivos, autocontrole e capacidade para tomar decisões. A terceira, a passividade dos usuários, sustentada na ideia de que são receptáculos passivos de informação objetiva, com a tarefa de receber em mãos pacotes de informações. A quarta, a trans-situacionalidade, em que se tenta predizer o comportamento dos usuários por meio de estatísticas e modelos que poderiam ser aplicados em várias situações. A quinta, a visão atomística da experiência, centrada na interação entre os usuários e os sistemas de informação. A sexta, a concepção comportamental em que se privilegia o comportamento externo, como contatos com fontes e usos de sistemas. A última, o caos, fundamentado na crença de que as pesquisas produzem observações sistemáticas e padrões de comportamento para os sistemas de informação.

As principais características identificadas no novo modelo, em oposição à abordagem tradicional, são as seguintes: aquela em que se reconhece a subjetividade humana resultante de uma realidade que não transmite significado constante; o construtivismo, em que o conhecimento não é visto como acabado, constituindo-se das interações do indivíduo com o meio pelo uso da linguagem; a visão dos usuários como seres ativos, direcionados por seus próprios objetivos e capacidade de escolhas próprias. A situcionalidade, que considera o comportamento informacional variável de acordo com a especificidade da situação; a visão holística, pela qual os usuários devem ser compreendidos em um contexto social mais amplo, e os sistemas, como um dos elementos a que podem recorrer se querem informação; o cognitivismo, baseado na crença de que as abordagens fundamentadas no comportamento e no desenvolvimento cognitivo podem contribuir substancialmente com a ciência da informação. Finalmente, a individualidade sistêmica, em que se reconhece a emergência da inclusão dos valores individuais.

O paradigma emergente, descrito anteriormente, foi construído pela análise da literatura evidenciada nas novas abordagens:

- valor atribuído pelo usuário: centrado na percepção do usuário sobre a utilidade e o valor do sistema de informação;

- sense-making: maneira como as pessoas dão significado ao mundo e ao uso da informação nesse processo;

- estado anômalo de conhecimento: análise de como as pessoas buscam informações relativas a situações em que seu conhecimento é incompleto.

Observa-se, assim, que a principal diferença entre as abordagens adotadas no paradigma tradicional e no paradigma emergente está vinculada aos aspectos psicológicos, em que se identifica a primeira como behaviorista e a segunda como cognitivista. Adicionalmente, é possível perceber, pela orientação metodológica, o positivismo permeando as pesquisas fundamentadas no paradigma behaviorista, no sentido em que se adotava, essencialmente, a abordagem quantitativa e o método hipotético-dedutivo. 
Os estudos centrados no paradigma cognitivista, por sua vez, provavelmente já influenciados pela fenomenologia, começam a se nortear por métodos qualitativos e indutivos, evidenciados nas abordagens descritas.

Ellis, Dervin, Kuhlthau e Wilson são alguns pesquisadores associados a essas mudanças. A partir de fins da década de 1980, os estudos orientados pelo ponto de vista cognitivo reconhecem que as necessidades de informação ocorrem tanto no âmbito cognitivo quanto no sociológico. As pesquisas buscavam conhecer as características únicas de cada usuário e o processo cognitivo comum à maioria deles, abordando questões como categorização técnica, memórias de curto e longo prazos, estilos de aprendizagem, motivação, tipos de personalidades e fatores semânticos (HEWINS, 1990).

Hewins (1990) publicou a $11 .^{a}$ revisão sobre necessidades e usos da informação, que cobriu o período de 1986 a 1989. Nesse intervalo de tempo houve mudanças significativas no modo como a informação era disseminada e na tecnologia disponível para buscá-la. O objetivo foi verificar a consolidação do novo paradigma, descrito por Dervin e Nilan (1986), e a contribuição de outras disciplinas, além da ciência da informação e biblioteconomia, pelo fato de os estudos estarem difundidos por muitas áreas de conhecimento. Condizente com esse processo de mudança, surgiram metodologias alternativas, como a linha do tempo, que retrata "cenas" ao longo de um período, permitindo identificar eventos críticos. É também o caso do uso de diários, apresentando todas as possíveis soluções para um problema particular e a opção escolhida para cada uma. Outra alternativa citada foi a técnica do incidente crítico. Hewins (1990) concluiu que a premissa de Dervin e Nilan (1986) sobre a mudança de paradigma era validada pelo surgimento de novas abordagens na literatura, mais centradas nos usuários do que nos sistemas e baseadas nos processos cognitivos. Os novos temas relacionavam-se às características dos usuários e como compreendê-los melhor, tendo caráter mais interdisciplinar que os anteriores.
Embora muitos dos novos autores estivessem fundamentados na abordagem cognitiva, em fins da década de 1980 surge a abordagem social. O eixo dos trabalhos ${ }^{2}$ situa-se nos significados e valores que os indivíduos atribuem ao contexto sociocultural, dentre outros. A abordagem pretendeu estudar os fenômenos que transcendiam a estrutura cognitiva. O trabalho de vanguarda foi desenvolvido por Chatman (1999), que propôs três estruturas para entender o comportamento informacional: "teoria da pobreza de informações", "teoria do ciclo da vida" e "teoria do comportamento normativo". Outra teoria que cresceu intensamente desde o início dos anos 90 foi a abordagem multifacetada, que percebe o comportamento informacional como um sistema complexo em que é necessária a integração de várias teorias para descrevê-lo (PETTTIGREW; FIDEL; BRUCE, 2001).

Ainda em meados da década de 90, o interesse em discutir as pesquisas e o desenvolvimento conceitual que fundamentavam os estudos se intensifica, como pode se observar em pelo menos três iniciativas. A primeira, em 1996, com a conferência intitulada Information Seeking in Context, realizada, a partir de então, bianualmente, em vários países da Europa. A segunda, em 1999, com o estabelecimento do grupo de estudos Information Needs, Seeking and Use (Siguse) pela American Society for Information Science (Asis), atual American Society for Information Science and Technology (Asist). A terceira, a edição especial do periódico Information Processing \& Management sobre Information Seeking in Context (PETTIGREW, FIDEL, BRUCE, 2001). Nota-se, portanto, uma espécie de institucionalização do tópico, devido à relevância que tais estudos representam, sem dúvida alguma, para a ciência da informação.

No final da década de 1990, as publicações de Wilson dão início a debates sobre a adequação do termo 'comportamento informacional' para se referir aos estudos de necessidade, busca e uso da

\footnotetext{
2 Os tópicos sobre abordagem social e multifacetada foram resumidos na revisão de Pettigrew, Fidel e Bruce (2001).
}

Ci. Inf., Brasília, DF, v. 39 n. 1, p.21-32, jan./abr., 2010 
informação. Os argumentos a favor observam que o campo de estudos estava se ampliando e precisava incluir conceitos sobre necessidades e oferta de informação. Os argumentos contrários sustentavamse na ideia de que o termo 'comportamento' poderia ser associado inapropriadamente ao paradigma behaviorista da psicologia. Da ótica semântica, o termo seria inadequado pelo fato de que informação não possui comportamento. No entanto, apesar das críticas, a expressão parece ter aceitação geral pelo uso em títulos de artigos e cursos acadêmicos.

\section{Estudos contemporâneos (2000 em diante)}

Na revisão de Pettigrew, Fidel e Bruce (2001), primeira da década de 2000, ratifica-se o uso do termo "comportamento informacional", que substituiu a tradicional expressão "necessidades e uso da informação" empregada no título de revisões anteriores. Seu objetivo foi verificar os avanços no desenvolvimento da estrutura conceitual do tópico a partir do paradigma centrado no indivíduo. Como resultado, os autores identificam três abordagens. A primeira, cognitiva, que examina o comportamento do sujeito a partir do conhecimento, convicções e crenças que medeiam as percepções de mundo. A segunda, social, baseada nos significados e valores que as pessoas atribuem aos vários contextos. Finalmente, a abordagem multifacetada, que integra múltiplas opiniões para a compreensão do comportamento informacional.

Os autores concluíram que outro 'salto quântico' ocorre na área do comportamento informacional, qualificado pelo núcleo centrado no usuário. Mais que isso, caracteriza-se, também, pela ênfase na interação entre os contextos cognitivo, social, cultural, organizacional, afetivo e fatores linguísticos, em que o fenômeno do comportamento informacional é parte do processo de comunicação do ser humano. Segundo os autores, a base teórica da ciência da informação sustenta-se na ideia de um campo ortogonal, que analisa o fenômeno da informação em diferentes cenários, usando perspectivas interdisciplinares como sugeriu Bates em 1999. Nesse sentido, a literatura reflete uma compreensão madura do fenômeno informação em termos de cognição, aspectos sociais e outros fatores, permanecendo a necessidade de aprofundarse em cada um deles. Pettigrew, Fidel e Bruce (2001) sugerem, ainda, que o desafio é prover orientações para os projetos de sistemas verdadeiramente centrados no usuário e que reflitam a sustentação teórica do comportamento informacional.

Após quatro anos da publicação de Pettigrew, Fidel e Bruce (2001), Case (2006) propôs outra revisão, identificando pesquisas que contemplavam três categorias: profissão (gerentes, cientistas), papel desempenhado (aluno, pacientes) e aspectos demográficos (idade, gênero, grupos étnicos). Para a análise dos conteúdos, o autor presumiu que o componente central do comportamento informacional é a noção de interação com um conjunto potencial de fontes que podem indicar os interesses e as necessidades de informação. Conclui que os estudos estão mais populares e contam com a participação de colaboradores de várias partes do mundo, diferentemente de 30 anos atrás, quando prevaleciam as pesquisas realizadas no Reino Unido. Case (2006) identificou a existência de quatro pontos relevantes: mais atenção no contexto e na influência social; mais esforços em entender a 'mente' do indivíduo; mais tempo gasto com os sujeitos individualmente, e maior profundidade da descrição global. Nesse sentido, as teorias de várias disciplinas têm sido fundamentais para o crescimento e a consolidação do tópico.

O autor conclui enfatizando a importância da precisão do título dos artigos. Para ele, muitos textos centrados na busca de informação na Internet são denominados 'comportamento informacional', acarretando uma banalização do conceito. Arguiu que coisas diferentes não podem ter o mesmo 'rótulo'. Comportamento informacional deve ser compreendido de modo mais amplo, e as pesquisas mais estritas devem ser inseridas como subtópicos.

Discutindo as implicações metodológicas da influência contextual apenas estreitamente ao tipo de abordagem empregada, Courtright (2007) intitula 
sua revisão 'o desafio do contexto nas pesquisas de comportamento informacional', na qual o termo pode ser compreendido sob quatro perspectivas:

$\left.1^{a}\right)$ contexto no sentido de contêiner refere-se à noção de que os elementos existem objetivamente em torno do ator e podem ser enumerados pelo pesquisador que o observou. Nessa perspectiva, comportamento informacional é descrito em termos das principais características do usuário, que, todavia, não são analisadas pelo contexto.

$\left.2^{a}\right)$ em outro aspecto, o do contexto compreendido como construção de significado, as atividades informacionais são relatadas considerando-se o modo como as influências e as variáveis são percebidas e construídas pelos indivíduos que buscam informação. Para a autora, o modelo falha por não suportar a complexidade, a variabilidade e as interações mútuas, tais como rede social, tecnologias da informação e práticas organizacionais.

$3^{\text {a) }}$ o terceiro sentido relaciona-se à construção social dos indivíduos, compreendidos como seres sociais que constroem a informação por meio da interação social, e não somente pelo que está 'dentro de sua cabeça'.

$\left.4^{a}\right)$ Por fim, a perspectiva do ser social pode ser ampliada para incluir o contexto relacional embeddedness -, abrangendo também as variáveis externas que influenciam a ação. Nessa dimensão, o contexto é a construção resultante da interseção do ponto de vista do indivíduo com o pesquisador.

Courtright (2007) observou os seguintes fatores e elementos mais citados que influenciam o contexto: papel desempenhado; recursos de informação (bibliotecas, livrarias, agências de informação); meio cultural; fatores sociais, como rede e capital social, normas e colaboração no trabalho; aspectos relacionados a tarefas, problemas, situações e tecnologias; e, por fim, a função no trabalho e a atividade humana. A autora concluiu, apresentando a consolidação do paradigma centrado no indivíduo e não mais nos sistemas como tendência identificada no estudo.
Há, no entanto, segundo Courtright (2007), o desafio de conceitualizar as formas de influência no contexto sem retornar à visão centrada nos sistemas, na qual as ações de informação são vistas como previsíveis conforme o conjunto de variáveis ambientais. Muitas pesquisas ainda continuam a comparar contexto com um conjunto de elementos físicos e a identificar uma ou mais variáveis como causas ou elementos tangencialmente relacionados à prática de informação do indivíduo. Mas existem diversos modelos e tendências teóricas que englobam a complexidade do contexto e percebem os indivíduos incluídos em um sistema complexo, múltiplo, sobreposto e dinâmico. Elementos como sociabilidade, cultura, normas organizacionais e recursos, assim como mudanças tecnológicas e relação de forças, não podem ser excluídos do processo de pesquisa. Essas novas tendências de investigação implicam novas metodologias e uso de múltiplos métodos, por exemplo, etnografia, observação e entrevistas.

A última revisão da primeira década do século XXI foi realizada por Fisher e Julien (2009) com análise de alguns trabalhos de 2004, e os demais entre 2005 e início de 2008. Embora ainda não publicada formalmente e não disponível em bibliotecas no Brasil, foi possível ter acesso ao texto por meio das próprias autoras. Nos trabalhos por elas selecionados, todos escritos em língua inglesa, foram observados os métodos de pesquisa, o contexto, o fator humano (acadêmicos, cientistas, estudantes, grupos profissionais, pessoas e a vida cotidiana, bem como as pessoas no contexto de saúde), fontes de informação, conceitos na pesquisa de comportamento informacional e estrutura conceitual.

Ao abordarem o tema, Fisher e Julien (op. cit) provêm definição bastante completa de comportamento informacional, a qual mostra, de fato, que o conceito abrange toda a gama de estudos relacionados com o usuário e a informação. Nesse sentido, inclui estudos das necessidades de informação, e de como as pessoas a buscam, gerem, fornecem e usam, tanto propositada quanto passivamente em sua vida diária. Em citação 
literal a Case (2006), as autoras ratificam a ideia de que o campo do comportamento informacional vem mostrando maturidade nas investigações pela atenção crescente dada às teorias na atualidade.

A revisão finaliza corroborando a contínua expansão das pesquisas de comportamento informacional em termos dos números de análises e de pesquisadores, como observado também por Case (2006). Priorizam-se fatores contextuais, na ênfase em abordagens construcionista e construtivista, e também na ampliação e no desenvolvimento de teorias e métodos. Isso porque estudos de usuários de informação na ciência da informação como um todo, considerando os grupos pesquisados, passaram a abranger tanto o contexto organizacional quanto o comunitário e o de negócios, e não somente o contexto acadêmico ou industrial, como nos primeiros tempos. Tal ampliação de foco, por sua vez, tende a se refletir nas abordagens de outros temas e tópicos da área.

\section{COMPORTAMENTO INFORMACIONAL: POR UMA PERSPECTIVA COMPLEXA}

O tema 'comportamento informacional' tem sido bastante explorado no Arist. Substitui a nomenclatura utilizada nos trabalhos anteriormente denominados 'necessidades e uso de informação'. Em termos quantitativos, foram 15 revisões até o momento, sendo que a década de 1970 mostra-se a mais profícua (cinco revisões) apesar de a década de 2000, ainda não completada, mostrar-se com boa produtividade (quatro). Considerando-se a evolução dos estudos de comportamento informacional desde a primeira revisão do Arist (1966), até a última, em 2009, percebem-se mudanças significativas no foco dos trabalhos, culminando nos seguintes pontos:

- pesquisas mais centradas no indivíduo;

- inclusão de outros grupos estudados, além de cientistas e tecnólogos;

- abordagem multifacetada, englobando os aspectos sociocognitivo e organizacional;
- compreensão do comportamento informacional como processo em que os indivíduos estão constantemente buscando e usando informações;

- ampliação dos estudos qualitativos, assim como do uso de múltiplos métodos;

- maior consistência teórica com aumento de fundamentação interdisciplinar,

- crescimento do número de pesquisas, em todas as partes do mundo.

Tais mudanças paradigmáticas começaram a germinar com a percepção das limitações impostas pelo instrumental teórico-metodológico na esteira da contestação dos principais postulados da concepção científica vigente em meados do século passado. A evolução conceitual dos 'estudos de usuários' para 'estudos de comportamento informacional' reflete a necessidade de se compreenderem os processos em uma perspectiva multidimensional. Isso porque ocorre profunda imbricação na tessitura dos fenômenos, em que vários fatores desempenham papéis decisivos na produção do conhecimento.

Essa multidimensionalidade, no entender de Morin (2000), considera a realidade antropossocial em várias dimensões: individual, social e biológica. Mais que isso, compõe-se de disciplinas especializadas, por exemplo, economia, psicologia e demografia como as diferentes faces e mesma realidade. Logo, as disciplinas precisam ser diferenciadas e tratadas como tais, não isoladas e incomunicáveis.

Como observado por Courtright (2007), os indivíduos vivem em um ambiente complexo, múltiplo, sobreposto e dinâmico, que requer novas metodologias e uso de múltiplos métodos. Nesse sentido, é importante destacar que tal contexto norteia tanto a construção teórica necessária aos estudos de comportamento informacional quanto o modo de se delinear a investigação.

É possível, portanto, concluir que o comportamento informacional, compreendido como processo natural do ser humano no papel de aprendiz da própria 
vida, requer visão ampla do pesquisador. Exige, ainda, o entendimento das relações estabelecidas em determinado espaço-tempo em que ocorrem ações de busca, uso e transferência de informação. Os indivíduos se engajam nessas ações quando têm necessidade de informação.

Contudo, se o processo é natural, a aprendizagem humana para gerenciar e usar as informações pode ocorrer de forma mais eficaz se houver sistematização e ensino desse conhecimento, isto é, se os sujeitos forem letrados informacionalmente. Nessa linha de pensamento, um dos desafios dos pesquisadores da ciência da informação é gerar conhecimento que possa ser utilizado em prol da conscientização, da educação e da construção da cidadania com o uso desse saber, com vistas a um mundo sustentável, ético e viável.

Artigo submetido em 05/03/2009 e aceito em 09/06/2010.

\section{REFERÊNCIAS}

ALLEN, Thomas J. Information need and use studies. Annual Review of Information Science and Technology, v.4, p. 3-29, 1969.

BATES, M. J. The invisible substrate of information science. Journal of the American Society for Information Science, v. 50, n. 12, 1999. Disponível em: <http://www.gseis.ucla.edu/faculty/ bates/substrate.html>. Acesso em: 08 ago. 2006.

BRITTAIN, J.M. Information and its users: a review with special reference to the social sciences. Bath: Bath University Press, 1970.

CHATMAN, Elfreda A. A theory of life in the round. Journal of the American Society for Information Science, n.50, v.3, p. $207-$ 217, 1999.

CASE, Donald O. Information Behavior. Annual Review of Information Science and Technology, v. 40, p. 293-327, 2006.

COURTRIGHT, Christina. Context in Information Behavior Research. Annual Review of Information Science and Technology, v. 41, p. 273-306, 2007.

CRANE, Diana. Information needs and uses. Annual Review of Information Science and Technology, v.6, p. 3-39, 1971.
CRAWFORD, Susan. Information needs and uses. Annual Review of Information Science and Technology, v. 13, p. 61-81, 1978.

DERVIN, Brenda; NILAN, Michael. Information needs and uses. Annual Review of Information Science and Technology, v.21, p. 3-33, 1986.

FIGUEIREDO, Nice Menezes de. Estudos de uso e usuários da informação. Brasília: IBICT, 1994.

FISHER, Karen; JULIEN, Heidi. Information Behavior. Annual Review of Information Science and Technology, v. 43, p. 317-358, 2009.

HERNER, Saul; HERNER, Mary. Information need and use studies in science and technology. Annual Review of Information Science and Technology, v.2, p. 1-34, 1967.

HEWINS, Elizabeth T. Information need and use studies. Annual Review of information Science and Technology, v.25, p. 145172,1990 .

KUHN, Thomas Samuel. A estrutura das revoluções cientificas. São Paulo: Perspectiva, 1962.

LIN, Nan; GARVEY, William D. Information need and use studies. Annual Review of Information Science and Technology, v.7, p. $5-37,1972$.

LIPETZ, Ben-Ami. Information needs and use. Annual Review of Information Science and Technology, v. 5, p. 3-32, 1970.

MARTYN, John. Information need and use studies. Annual Review of Information Science and Technology, v. 9, p. 3-23, 1974.

MENZEL, Herbert. Information needs and uses in science and techonology. Annual Review of Information Science and Technology, v.1, p. 41-46, 1966.

MORIN, Edgar. Ciência com consciência. 6 ed. Rio de Janeiro: Berthand Brasil, 2000.

PAISLEY, W. Information needs and uses. Annual Review of Information Science and Technology, v. 3, p. 1-30, 1968.

PETTIGREW, Karen E.; FIDEL, Raya; BRUCE, Harry. Conceptual frameworks in information behavior. Annual Review of Information Science and Technology, v. 35, p. 43-78, 2001.

WILSON, T.D. Human information behavior. Informing Science Research, v.3, n.2, p. 49-55, 2000.

. Models in information behaviour research. Journal of Documentation, v.55, n.3, p. 249-270, jun. 1999.

WILSON-DAVIS, K. The centre for research on user studies: aims and functions. Aslib Proceedings, v. 29, n. 2, p. 67-76, fev. 1977. 